\title{
Women's Views on Mode of Birth in Public Hospitals in Argentina: Inputs From a Formative Research to Optimize the Use of Caesarean Section
}

Carla Perrotta ( $\sim$ carla.perrotta@ucd.ie)

University College Dublin, National University of Ireland

Mariana Romero

Centro de Estudios de Estado y Sociedad (CEDES)- CONICET (Consejo Nacional de Investigaciones Científicas y Tecnológicas)

Yanina Sguassero

Centro Rosarino de Estudios Perinatales

\section{Natalia Righetti}

Centro de Estudios de Estado y Sociedad (CEDES)- CONICET (Consejo Nacional de Investigaciones Científicas y Tecnológicas)

\section{Celia Gialdini}

Centro Rosarino de Estudios Perinatales

\section{Betrán AP}

UNDP, UNFPA, UNICEF, World Health Organization

\section{Silvina Ramos Ramos}

Centro de Estudios de Estado y Sociedad (CEDES)- CONICET (Consejo Nacional de Investigaciones Científicas y Tecnológicas)

\section{Research Article}

Keywords: Public Hospitals, Caesarean Section, Argentina

Posted Date: April 23rd, 2021

DOI: https://doi.org/10.21203/rs.3.rs-429612/v1

License: (c) (1) This work is licensed under a Creative Commons Attribution 4.0 International License. Read Full License 
Women's views on mode of birth in public hospitals in Argentina: inputs from a formative research to optimize the use of caesarean section

Perrotta Carla ${ }^{1 *}$, Romero $\mathrm{M}^{2}$, Sguassero $\mathrm{Y}^{3}$, Righetti $\mathrm{N}^{4}$, Gialdini $\mathrm{C}^{3}$, Betrán $\mathrm{AP}^{5}$, Ramos $\mathrm{S}^{4}$.

${ }^{1}$ School of Public Health, University College Dublin, National University of Ireland, Dublin, Ireland. E-mail: carla.perrotta@ucd.ie

${ }^{2}$ Centro de Estudios de Estado y Sociedad (CEDES)- CONICET (Consejo Nacional de

Investigaciones Científicas y Tecnológicas), Buenos Aires, Argentina. E-mail: mromero@cedes.org

${ }_{3}^{3}$ Centro Rosarino de Estudios Perinatales, Rosario, Argentina. E-mail: ysguassero@crep.org.ar;

cgialdini@crep.org.ar.

${ }^{4}$ Centro de Estudios de Estado y Sociedad (CEDES), Buenos Aires, Argentina. E-mail:

natirighetti@gmail.com; silvinaramosarcoiris@gmail.com

${ }^{5}$ UNDP, UNFPA, UNICEF, WHO, World Bank Special Program of Research, Development and

Research Training in Human Reproduction, Department of Reproductive Health and Research, World

Health Organization, Geneva, Switzerland. E-mail: betrana@who.int

*Corresponding autor

\section{Abstract}

Background: This paper reports on women's perspectives on the birth mode in five public maternity hospitals in Argentina. The study is a formative research study component aimed at tailoring interventions to reduce unnecessary caesarean section (CS) use.

Methods: Participants were postpartum women aged $\geq 15$ years old in five hospitals in the provinces of Salta, Corrientes, Tucuman, Santa Fe and Buenos Aires City. Hospitals completed an institutional survey indicating the availability of obstetric services. The fieldwork was carried out from November 2018 to June 2019. Trained interviewers gathered data on obstetric history, companionship, mode of delivery preferences, and general opinion on vaginal and caesarean section births through semi-structured interviews. The interviews were coded and analysed with standard quantitative methods.

Results: The five hospitals had a CS rate between 29.2 and 45.5. Four institutions indicated limited access to epidural and other pain management strategies and a restricted antenatal education schedule.

The sample included 621 postpartum women with a mean age of 26 years ( \pm SD 6 ). $60 \%$ of them had a vaginal birth (VB). More than $90 \%$ of women in three hospitals favoured VB, and 
in two, 67\% ( $<<0001)$. CS preference was associated with giving birth in those two hospitals and the numbers of miscarriages adjusting by maternal age and previous pregnancies. The reasons for preferring a VB included faster recovery, feeling ready, and considering it more natural. Most women chose CS as the best mode of birth to avoid birth pain. CS disadvantages included post-procedure pain, dependence on others to take care of her or the baby afterwards, and prolonged time in the hospital. Six out of ten women would have liked to be asked by their providers about the MOB of choice.

Conclusions: Women giving birth in public maternity hospitals of Argentina preferred a vaginal delivery to a caesarean section. There is an ongoing need to improve access to pain management during labour and vaginal birth and include women's opinions along the decision-making process for selecting the mode of childbirth. Hospitals with a lower preference for VB will require additional efforts to understand women's needs and values.

Trial registration: IS002316 


\section{Background}

During the past century, childbirth changed from being a natural and domestic experience to a medical and professional act. Progress in medical interventions and technology in childbirth

5 led to improvements in women and children's life and health. The introduction of safe caesarean section (CS) was a critical development of that process, and, today, CS is at the centre of emergency obstetric care. However, its overuse in low-risk pregnancies is problematic, since the procedure increases the risk of short-term and long-term comorbidities (1-3). The Latin American region has rapidly adopted CS, reporting the most significant

10 increase in CS rates during 1990-2014 (4). Studies based on Latin-American data suggested that the private healthcare sector drives CS use (5-8). However, in Argentina, public hospitals increased surgical births by $22 \%$ in $2010-2017(9,10)$, exceeding the global CS rate growth (4).

A decade ago, a cross sectional study in Buenos Aires City indicated that, in overall, $92 \%$ of

15 women preferred vaginal birth (VB) over CS with no differences between private and public facilities (11), a rate similar to Nordic countries in Europe and other developed countries $(12,13)$. It is uncertain if women preferences have since then evolved and if we can attribute the increasing trend in public hospitals to a shift in mode of birth (MOB) preferences in the public sector. There are also uncertainties about how the contextual factors related to the

20 limited access to obstetric care services -like pain management or antenatal education- in the public sector in Argentina may influence decision-making.

We conducted a formative research study in public hospitals in Argentina which included women, healthcare professionals and hospital administrators to understand the contributing factors related to the increase of CS rates in Argentina and the barriers and facilitators for the

25 implementation of interventions aiming at optimizing its use (14). This research aims to contribute to the tailoring of interventions and to inform the development of protocols and 
guidelines in Argentina. This paper presents the findings of semi-structured interviews (SSI) to gain understanding on women's preferences and their views and opinions on the MOB.

\section{Methods}

\section{Semi-structured interviews}

The detailed methodology of the formative research study carried out in maternity hospitals of Argentina has been published elsewhere (14). In brief, 19 hospitals purposely selected participated and collected data on the availability of services and resources in the facilities and health providers' views on CS determinants. In addition, five hospitals identified as

35 Hospitals A, B, C, D and E were selected among the initial 19 for a more in-depth assessment of health care professionals' views and opinions regarding CS determinants and interventions. Additionally, as part of the data collected in this subgroup of hospitals, women's views and opinions about MOB and their reasons were explored (Additional file 1)

The adopted strategy for recruitment during this formative research was selecting one woman

40 out of four who had a vaginal or CS delivery every day of the week during three consecutive months or until 130 consecutive cases in each hospital were included (whichever criterion was met first). The SSI was applied by a professional trained for this task (social worker, psychologist, or nurse) who was not a member of the OB/GYN service to prevent any bias and to preserve confidentiality. The fieldwork started in November 2018 and finished in June

45 2019, with hospitals entering the study at different months.

The inclusion criteria were (a) pregnant woman who had a delivery (vaginal or CS) at the participating hospital, (b) aged $\geq 15$ old, (c) new-born not requiring hospitalisation in the neonatal intensive care unit, and (d) obtaining informed consent.

A SSI was used to facilitate data gathering and engagement in a conversation with one

50 participant at a time (15). It consisted of 21 closed questions and seven open questions. The variables included were the following: (a) reproductive history, (b) opinions and preferences 
regarding vaginal and CS delivery, (c) labour and delivery process (including companionship), (d) their understanding of the reasons to perform a caesarean section, vaginal and CS delivery advantages and disadvantages, and (e) women's general opinion on

55 MBO. Two researchers (MR and NR) independently coded the open-ended questions. Coding was compared, and disagreements were solved by discussion until consensus was reached. Data were imported into a database in a standard quantitative format respecting multiple answers when applied. The reporting of the methods and results follows the standards of reporting of cross-sectional surveys (16).

\section{Statistical analysis}

Continuous variables were expressed as mean \pm standard deviation (SD) or median (range), and categorical variables as frequencies. Chi-square test was used for study group comparisons.

The preference of MOB was assessed using univariate and multivariate analyses. A logistic

65 regression model explored the association between MOB preferences and maternal obstetric history (parity, history of miscarriage), maternal age, hospital, and delivery mode of index birth. The delivery hospital was included as a dummy variable with Hospital $\mathrm{C}$ as the reference and $\mathrm{VB}$ as the reference for delivery mode $(\mathrm{OR}=1.00)(17)$. Odds ratio $(\mathrm{OR})$ with $95 \%$ confidence interval (CI) for binary outcomes and weighted mean difference (WMD) for

70 continuous outcomes were estimated. All statistical tests of hypotheses were two-sided, and the criterion for statistical significance was set to $\alpha=0.05$. Statistical analyses were carried out with Stata version 15.

$\underline{\text { Ethical approval and consent }}$

Ethical approvals from the Independent Ethical Committee of the Centro Rosarino de

75 Estudios Perinatales (Argentina), the Research Project Review Panel of the UNDP/UNFPA/UNICEF/WHO/World Bank Special Programme of Research, Development 
and Research Training in Human Reproduction, at the Department of Sexual and Reproductive Health and Research at the World Health Organization, the Research Ethics Review Committee of the World Health Organization, and the provincial and ethical

80 committees of each of the participating hospitals were obtained. All the procedures in this study were in accordance with the ethical standards of the mentioned research ethics committee and with the Helsinki Declaration. All women signed an informed consent, and anonymity was ensured by not including any personal data such as name, date of birth and mandatory signature. The participant hospitals are anonymized.

\section{$85 \underline{\text { Results }}$}

The characteristics of the hospitals from which women were recruited are described in Table 1. Their median birth by CS was 39.5\% $(29.9 \%-45.5 \%)$. The number of live births ranged from 1100 to 7900 per year. The hospitals are free of charge at the point of care, though they widely differed in workforce numbers and services. The total number of midwives,

90 obstetricians and residents working in maternal care varied from 8.8 to 40.7 per 1000 live births, while the number of midwives ranged from 0 to 8 per 1000 live births. Only one hospital (Hospital C) had comprehensive pain management interventions available to women 24 hours -including access to hot water showers and epidural - and offered an extended schedule of antenatal education. The other four hospitals had limited availability to epidural

95 or non-medical pain management interventions and provided a restrictive antenatal education schedule (e.g. one morning per week). None of the five hospitals guaranteed companionship during CS, and only two ensured 24/7 that women had someone of their choice during birth. The five hospitals reported to provide safe emergency caesarean surgeries $24 / 7$ and to have access to emergency anaesthetists and surgeons, equipped operating rooms, blood bank,

100 neonatal and adult Intensive Care Units. The embolization of the uterine artery was available in only one hospital (Hospital C). 
Table 1. Baseline characteristics of participating hospitals.

\begin{tabular}{|c|c|c|c|c|c|}
\hline & Hospital A & $\begin{array}{l}\text { Hospital } \\
\text { B }\end{array}$ & Hospital C & $\begin{array}{l}\text { Hospital } \\
\text { D }\end{array}$ & $\begin{array}{l}\text { Hospital } \\
\text { E }\end{array}$ \\
\hline Number of live births (2017) & 1220 & 2798 & 7930 & 2200 & 3467 \\
\hline CS rates $(2017)$ & 41.3 & 37.6 & 29.2 & 42.3 & 45.5 \\
\hline Number of midwifes/1000 live births & 13.1 & 0 & 1.6 & 0 & 7.2 \\
\hline Number of OB/GYNs /1000 live births & 16.3 & 8.5 & 3.6 & 6.8 & 6.6 \\
\hline $\begin{array}{l}\text { Number of trainees in OB/GYNs /1000 live } \\
\text { births }\end{array}$ & 11.4 & 4.6 & 3.5 & 0 & 0 \\
\hline Access to emergency CS & yes & yes & yes & yes & yes \\
\hline Access to epidural 24 hours* & no & no & yes & no & no \\
\hline $\begin{array}{l}\text { Access to hot shower facilities during birth } 24 \\
\text { hours* }\end{array}$ & no & no & yes & no & no \\
\hline $\begin{array}{l}\text { Access to massage, relaxation for pain } \\
\text { management } 24 \text { hours }\end{array}$ & no & no & yes & no & no \\
\hline Antenatal education offered daily $\mathrm{am} / \mathrm{pm}$ & no & no & yes & no & no \\
\hline Companionship during VB 24 hours* & yes & no & yes & no & no \\
\hline Companionship during CS 24 hours* & no & no & no & no & no \\
\hline
\end{tabular}

CS: caesarean section; VB: vaginal birth; OBY/GY: Specialist in Obstetrics and Gynaecology

* All interventions were delivered 7 days/week unless otherwise indicated.

110 The 621 participating women gave written informed consent. Their mean age sample was 26 \pm SD 6 (12.4\% were adolescents). Six out of ten had a VB in the index pregnancy. The median number of previous pregnancies was 1.2 (range 0 to 7). Most women who underwent a VB had someone of their choice during birth $(\mathrm{N}=314,88.5 \%)$ compared with only a third of 
those who had a CS $(\mathrm{N}=213,34.3 \%)(\mathrm{p}<0.00001)$. In Hospitals $\mathrm{B}, \mathrm{C}$, and $\mathrm{E}$ most women

115 having a CS did not have companionship during birth (Table 2).

Table 2. Characteristics of the study sample.

\begin{tabular}{|c|c|c|c|c|c|c|}
\hline & Total & $\begin{array}{l}\text { Hospital } \\
\text { A }\end{array}$ & Hospital B & $\begin{array}{l}\text { Hospital } \\
\text { C }\end{array}$ & $\begin{array}{l}\text { Hospital } \\
\text { D }\end{array}$ & Hospital E \\
\hline $\begin{array}{l}\text { Number of } \\
\text { women } \\
\text { interviewed }\end{array}$ & $\begin{array}{l}621 \\
(100)\end{array}$ & $\begin{array}{l}130 \\
(20.9)\end{array}$ & $127(20.4)$ & $129(20.7)$ & $101(16.2)$ & $134(21.5)$ \\
\hline Age, mean (SD) & $26 \pm 6$ & $27.4 \pm 5$ & $25.4, \pm 5$ & $26 \pm 6$ & $25 \pm 5$ & $26 \pm 6$ \\
\hline $\begin{array}{l}\text { Adolescents (15- } \\
19 \text { years of age) }\end{array}$ & $\begin{array}{l}77 \\
(12.4)\end{array}$ & $9(6.9)$ & $17(13.3)$ & $17(13.1)$ & $12(11.8)$ & $22(16.8)$ \\
\hline $\begin{array}{l}\text { Parity, median } \\
\text { (range) }\end{array}$ & $1(0-6)$ & $2(0-6)$ & $1(0-5)$ & $1(0-6)$ & $1(0-6)$ & $1(0-5)$ \\
\hline $\begin{array}{l}\text { VB in the index } \\
\text { pregnancy }\end{array}$ & $\begin{array}{l}355 \\
(57.1)\end{array}$ & $69(53)$ & $74(58,6)$ & $68(52)$ & $64(63)$ & $80(59.6)$ \\
\hline $\begin{array}{l}\text { Women with } \\
\text { previous CS, N } \\
(\%)\end{array}$ & $\begin{array}{l}171 \\
(40.6)\end{array}$ & $41(40.5)$ & $30(36.1)$ & $31(35.2)$ & $20(32.7)$ & $49(55.6) 1$ \\
\hline Preference for VB & $\begin{array}{l}467 \\
(75.2)\end{array}$ & $119(91)$ & $87(69) 2$ & $108(92)$ & $82(93)$ & $71(64) 2$ \\
\hline Neutral & $50(8)$ & 0 & 2 & $12(9)$ & $12(11)$ & $24(17.9)$ \\
\hline $\begin{array}{l}\text { Was accompanied } \\
\text { during birth by } \\
\text { someone of her } \\
\text { choice* }\end{array}$ & $\begin{array}{l}404 \\
(65.1)\end{array}$ & $\begin{array}{l}94 \\
(72.3)\end{array}$ & $73(57)$ & $65(50.4)$ & $95(94.1)$ & $77(57)$ \\
\hline $\mathrm{VB}^{3}$ & $\begin{array}{l}314 \\
(88.5)\end{array}$ & $\begin{array}{l}50 \\
(72.5)\end{array}$ & $70(94.6)$ & $60(88)$ & $63(98.4)$ & $71(88)$ \\
\hline $\mathrm{CS}^{3}$ & $\begin{array}{l}213 \\
(34.3)\end{array}$ & $44(72)$ & $3(5.7)$ & $5(8)$ & $32(86.5)$ & $6(11)$ \\
\hline
\end{tabular}

CS: caesarean section; VB: vaginal birth

$\mathrm{N}(\%)$

1 Compared against all the other hospitals statistically significant (p0.0001 chi square).

2 Compared against all other hospitals statistically significant (p0.0001 chi square).

3 Percentage of women that reported being accompanied during birth \% over the total number of births on that MOB in that hospital or the total

*4 women ( 3 in Hospital B and 1 in Hospital E) did not answer this question. 
Women preferred VB to a CS $(\mathrm{N}=467,75 \%)$; however, we observed differences across hospitals. In Hospitals A, C and D, more than $90 \%$ preferred VB over CS, whereas in 120 hospitals $\mathrm{B}$ and $\mathrm{E}$ this preference was lower, $64 \%$ and $69 \%$ respectively $(\mathrm{p}=0.001)$. Vaginal birth preference was associated with vaginal birth on the index pregnancy $(\mathrm{ORa}=2.06,95 \%$ CI 0.93 - 4.55). The variables associated to CS preference were giving birth in Hospital B (ORa $0.14,95 \%$ CI $0.05-0.40)$ and $\mathrm{E}$ (ORa 0.09, 95\% CI $0.03-0.25$ ), and the number of previous miscarriages $(\mathrm{ORa}=0.58,95 \% \mathrm{CI} 0.34$ - 0.99), (Table 3).

Table 3. Mode of birth preference. Univariate and Multivariate analysis

\begin{tabular}{|l|l|l|}
\hline & $\begin{array}{l}\text { Univariate analysis } \\
\text { OR }(95 \% \mathrm{CI})\end{array}$ & $\begin{array}{l}\text { Multivariate analysis } \\
\text { OR }(95 \% \mathrm{CI}) *\end{array}$ \\
\hline Woman age & $1.0(0.97-1.04)$ & $1.02(0.97-1.06)$ \\
\hline $\begin{array}{l}\text { Number of previous } \\
\text { miscarriages }\end{array}$ & $0.88(0.59-1.60)$ & $0.58(0.34-0.99)$ \\
\hline $\begin{array}{l}\text { MOB in the index } \\
\text { pregnancy** }\end{array}$ & $3.96(2.50-6.28)$ & $2.06(0.9-4.55)$ \\
\hline $\begin{array}{l}\text { Number of previous } \\
\text { pregnancies }\end{array}$ & $1.08(0.92-1.27)$ & Excluded \\
\hline $\begin{array}{l}\text { Hospital in which birth } \\
\text { took place }\end{array}$ & & \\
$\quad \begin{array}{l}\text { Hospital C } \\
\text { Hospital B }\end{array}$ & $0.90(0.35-2.25)$ & reference \\
Hospital A & $0.2(.10-0.40)$ & $0.14(0.05-0.4)$ \\
Hospital D & $1.10(0.44-2.77)$ & $0.70(0.21-2.37)$ \\
Hospital E & $0.16(0.40-2.90)$ & $0.85(0.81-3.17)$ \\
\hline
\end{tabular}

MOB: mode of birth

*Vaginal birth as the reference group

** Vaginal birth as the reference group

${ }^{* * *}$ Hospital C as a reference for the study site.

125 The most frequently mentioned reasons to prefer VB (N=467, 75\%) were faster recovery (mentioned by $\mathrm{N}=263,56.3 \%)$ and more natural/feeling ready $(\mathrm{N}=137,29.3 \%)$. Women also expressed their opposition to a surgical procedure such as a CS -more pain after birth/ I cannot walk or move straightaway after birth/ /longer stay in the hospital $(\mathrm{N}=152,32 \%)$.

The most frequent reasons for a CS preference $(\mathrm{N}=104,16.7 \%)$ fell under two domains: birth experience and safety. The former included not having to go through contractions/not feeling 
pain during birth $(\mathrm{N}=32,30.7 \%)$ and faster procedure $(\mathrm{N}=20,18 \%)$. The latter included feeling the procedure is safer $(\mathrm{N}=42,40.3 \%)$ and the doctor controls the procedure $(\mathrm{N}=15$, $14 \%$ ). Interesting, only women who gave birth at the two hospitals with the lowest preference for VB (Hospital B and Hospital E) explained their preferences using safety as the main 135 reason $($ Table 4$)$

Table 4. Women's preference and reasons according to mode of birth

\begin{tabular}{|l|l|}
\hline $\begin{array}{l}\text { VB preference }(\mathbf{N}=\mathbf{4 6 7}, \mathbf{7 5 \%}) \\
\text { VP in index pregnancy 293 (62.7\%) } \\
\text { CS in index pregnancy } 174(37.3 \%)\end{array}$ \\
\hline Faster recovery after birth & $263(56.3 \%)$ \\
\hline $\begin{array}{l}\text { CS more painful /CS limited autonomy after } \\
\text { birth /more time in hospital }\end{array}$ & $152(32 \%)$ \\
\hline More natural & $137(29.3 \%)$ \\
\hline $\begin{array}{l}\text { CS preference (N=104, 16.7\%) } \\
\text { VP in index pregnancy: 31 (29.8) } \\
\text { CS in index pregnancy: } 73(70.1)\end{array}$ \\
\hline Not feeling birth pain & \\
\hline Safer procedure & $32(30.7 \%)$ \\
\hline Faster procedure & $42(40.3 \%)$ \\
\hline The doctor oversees the procedure & $20(18 \%)$ \\
\hline
\end{tabular}

CS: caesarean section; VB: vaginal birth

${ }^{1}$ Women gave more than one reason to express their preferences.

Regardless of their own preferences and/or experience, women were also asked about their general opinions on the advantages and disadvantages of both vaginal and caesarean section deliveries (Table 5). The advantages for $\mathrm{VB}$ were faster recovery $(\mathrm{N}=438,70 \%)$, more natural than a $C S(\mathrm{~N}=311,49 \%)$, less pain after birth $(\mathrm{N}=305,48 \%)$, requires less time at the

140 hospital $(\mathrm{N}=272,44 \%)$, being able to move right after birth $(\mathrm{N}=274,43 \%)$, and partner can be present at birth $(\mathrm{N}=239,38 \%)$. The advantages for $\mathrm{CS}$ included no pain $(\mathrm{N}=207,33 \%)$, faster procedure $(\mathrm{N}=194,30 \%)$, can schedule the birth date $(\mathrm{N}=189,29 \%)$, no contractions $(\mathrm{N}=181,29 \%)$, safer $(\mathrm{N}=119,19 \%)$, can save the baby $(\mathrm{N}=115,18 \%)$, and miscellaneous answers concerned to the body appearance after VB such as it does not change your body or no perineal tears $(\mathrm{N}=29,4 \%)$. 
Pain was the most mentioned disadvantage for $\mathrm{VB}(\mathrm{N}=331,53 \%)$. It is worth noting that for a third of the women, VB did not have any disadvantage $(\mathrm{N}=183,29.4 \%)$ and a handful mentioned perineal tears and discomfort with examination. The cited burden of CS referred to the loss of independence right after CS, impacting on the ability to care for the baby - can't

150 look after the baby or myself- and to the prolonged hospital stay compared to VB -longer stay in the hospital $(\mathrm{N}=503,81 \%)$.

Six out of ten women responded they would have liked to be asked about their preferable MOB (N=363, 58.4\%), and only 18 out of 621 answered 'I don't know'. The most common reason was the right of women to choose and have her voice considered and valued $(\mathrm{N}=242$,

$15538 \%)$.

Lastly, women were asked about the circumstances in which a CS is needed. Overall, women cited medical conditions like woman with severe disease/risk for the woman $(\mathrm{N}=345,55 \%)$, baby is "seated" $(\mathrm{N}=267,42 \%)$, nuchal cord $(\mathrm{N}=239,38 \%)$, birth date overdue $(\mathrm{N}=201$, $32 \%)$, prolonged labour/women exhaustion $(\mathrm{N}=193,31 \%)$, or having had a previous CS $160 \quad(\mathrm{~N}=142,22 \%)$.

Table 5. Women's answers on advantages and disadvantages of vaginal and caesarean section deliveries ${ }^{1}$ irrespective of preferable mode of birth.

\begin{tabular}{|l|l|}
\hline VB advantages $(\mathbf{N}=\mathbf{6 2 1}) *$ & $\mathrm{~N}=\%$ \\
\hline Faster recovery & $438(70 \%)$ \\
\hline More natural mode of delivery & $311(49 \%)$ \\
\hline Less pain after birth & $305(48 \%)$ \\
\hline Less time at the hospital & $272(44 \%)$ \\
\hline Regaining independence after birth & $274(43 \%)$ \\
\hline Partner can be present & $239(38 \%)$ \\
\hline CS advantages (N=621) & \multicolumn{2}{|l}{} \\
\hline Not feeling birth pain & $194(34 \%)$ \\
\hline Faster process & $189(29 \%)$ \\
\hline Birth date predictable &
\end{tabular}




\begin{tabular}{|l|l|}
\hline Not feeling uterine contractions & $181(29 \%)$ \\
\hline Safe & $119(19 \%)$ \\
\hline $\begin{array}{l}\text { Can save the baby if an obstetrical } \\
\text { emergency occurs }\end{array}$ & $115(18 \%)$ \\
\hline No perineal tears & $29(4 \%)$ \\
\hline
\end{tabular}

CS: caesarean section; VB: vaginal birth

*Participants indicated more than one advantage

\section{$\underline{\text { Discussion }}$}

165 In the context of a steady increase in CS rates in Argentina, this study explored women's birth preferences and characterised obstetric services in five public hospitals in different country regions. The services provided were comprehensive to respond to obstetric emergencies. However, they have limitations to ensure adequate antenatal education and a holistic approach to pain management during birth. Additionally, only two hospitals guaranteed

170 constant companionship in the delivery ward. The included hospitals worked under significant demand pressure with limited human resources. Only one (Hospital C) had the number of staff per live births closer to high-income countries. The characterisation of services highlights the difficulties of ensuring that women receive continuous emotional support and encouragement during birth either by trained professionals or by someone of

175 their choice with the appropriate training to provide that support. Both interventions can reduce the use of unnecessary CS as well as improve the birth experience (18).

Despite these barriers, women in this sample preferred VB over CS. In three hospitals, nine out of ten women favoured VB over a CS. This finding is similar to the only study available addressing birth preferences in Argentina conducted a decade ago and also to women's

180 preferences in European countries (11-13). Women's preference for a VB in the two other hospitals was $20 \%$ lower, which is closer to postpartum preferences in China (19) or Italy (20) but higher than Brazil (13).

Women's age or previous pregnancies did not explain these differences. However, favouring 
CS was associated with giving birth in the two hospitals with higher preference for CS

185 adjusting for age, previous CS, and pregnancy type on the index pregnancy.

The difference in MOB preferences across hospitals is challenging to interpret. The two hospitals in which women had a higher inclination for CS are in different regions of the country and had different human resource structure (one hospital had midwives in their team, and the other did not). They share similar features to hospitals with higher VB preferences,

190 such as CS rates higher than $37 \%$, limited availability for pain management, and reduced antenatal education. Women did not differ in age or number of previous pregnancies.

We did not investigate the reasons for choosing the birth hospital. Women with a higher preference for CS may choose a hospital that may facilitate their request for CS. To the best of our knowledge, this is the first study showing that even in hospitals with similar financing

195 structure and limited provision of pain management during birth, women have different MOB preferences across hospitals. However, despite the observed differences between settings, most women favour VB.

In this study, women accounted for their preference for vaginal deliveries describing a feeling of being prepared and ready; they also value the possibility of a fast recovery and breastfeed.

200 The negatives attributes of VB, as expected, focused on pain during birth.

The positive account for CS preference was the possibility of analgesia. Women's reports on pain during and after birth were consistent and repetitive across all participants regardless of their age, MOB, and previous pregnancies. It is also a frequent narrative of women across countries and regions irrespective of their MOB preference $(12,19-22)$. Four of the five 205 participating hospitals had no epidural access by request, hot shower, massages, relaxation, or hypnosis, resulting in sub-optimal pain management during labour. This lack of pain management options is consistent with 'pain' as the recurrent reason women prefer a CS across the world $(19,24)$. A qualitative study by Wang (21) also discusses how limited access 
to pain relief is a potential determinant of surgical birth. Given these consistent findings,

210 policymakers, managers, and healthcare teams need to be aware and address pain management during and after birth as an essential component of obstetric care, which means that institutions need adequate resources.

When asked about the consequences of both CS and VB, most women focused exclusively on short-term effects. Women in this sector usually do not have additional support to look after

215 their new-borns and themselves after a surgery. We did not explore the support provided by the obstetric services to women that just have a CS. It is also possible that women lack of awareness of long-term risks. Our finding on women's emphasis on immediate consequences is consistent with previous studies in other countries that show that longer-term effects are under-reported $(22,25,26)$.

220 In line with studies in other settings, the significant finding of our study is that six out of ten women would have wanted to be asked about birth preference (27-29). The message reinforces the need to tailor interventions targeting women so as to include them as an active participant in health care decisions and confirms women's expectations for communication and informed dialogue with healthcare providers (30).

225 There are some limitations to the study. This sample represents women who had an uneventful pregnancy and delivered a healthy new-born; women with traumatic birth experiences or experiences in the Intensive Care Unit may have different accounts regarding MOB preferences, birth experience and perception of safety.

A starting point for hospitals intending to reduce unnecessary CS should include gathering 230 information on how women shape their preferences and their value when facing MOB decisions. We have shown that women's preferences in most hospitals have remained unchanged in 20 years. Thus, the CS rates changes cannot be attributed to change in preferences (11). There is an urgent call to include a care model that allows women to 
express their birth preferences model. Pregnant women need access to antenatal care to

235 discuss pain management options available to them $(31,32)$.

\section{Conclusions}

This study reinforces the evidence that women prefer CS over VB even in contexts in which the provision of services do not include a holistic approach to pain management during birth, comprehensive antenatal education and -in some cases- companionship. Women indicated

240 they want to be asked about their birth preference calling for services to incorporate women into the decision-making process during the antenatal period.

List of abbreviations: CS: caesarean section; MOB: mode of birth; OB/GYN: specialist in Obstetrics and Gynaecology; SSI: semi-structured interviews; UNDP: United Nations Development Programme; UNFPA: United Nations Fund for Population Activities; UNICEF: United Nations International Children's Emergency Fund; VB: vaginal birth; WHO: World Health Organization.

\section{Declarations:}

\section{Ethics approval and consent to participate}

The research study has ethical approval from the Independent Ethical Committee of the Centro Rosarino de Estudios Perinatales (Argentina), the Research Project Review Panel (RP2) of the UNDP/UNFPA/UNICEF/WHO/World Bank Special Programme of Research, Development and Research Training in Human Reproduction, at the Department of Sexual and Reproductive Health and Research at the World Health Organization, the Research Ethics Review Committee (ERC) of the World Health Organization, and the provincial and local ethical committees of each of the participating institutions. Women signed an informed consent, and anonymity was ensured by not having any personal data linked to them. In line with current Argentinean laws, adolescents aged 15 to 17 were included if they agreed to participate and obtain informed consent from their parents or legal guardians.

\section{Consent for publication}


Not applicable

\section{Availability of data and materials}

The data is stored on CEDES' server, encrypted. CEDES is the guardian of the dataset. Data is anonymised. Our data collection forms did not include any variable that could reveal the identity of the participants. The datasets generated and/or analysed during the current study are not publicly available due requests from the participating hospitals but are available from the corresponding author on reasonable demand.

\section{Competing interests}

The authors declare that they have no competing interests.

\section{Funding}

This research was funded by the UNDP-UNFPA-UNICEF-WHO-World Bank Special Programme of Research, Development and Research Training in Human Reproduction (HRP), a cosponsored programme executed by the World Health Organization (WHO) in the Department of Sexual and Reproductive Health and Research (SRH). Righetti N. is a research fellow funded by the Ministry of Health, Buenos Aires City Government. Dr Carla Perrotta also received funds to complete this research from the University College Dublin (UCD), College of Health Sciences, SEED Fund (2019). The contents of this article are solely the responsibility of the authors and do not reflect the views of the referred program or the other funding institutions.

\section{Author contributions}

SR and APB delineated the original research and research program outline. MR, SR, CP, YS have written the study protocol. APB contributed to improvements on the original protocol. MR, YS, CG coordinated the fieldwork. YS, CG, NR conducted the fieldwork. MR has coordinated the coding of the semi-structured interviews. CP conducted the data analysis and oversaw the completion of the database. CP and MR wrote the first version of the manuscript. All authors have contributed to, read and approved the final manuscript.

\section{Acknowledgements}

We thank Mercedes Vila Ortiz for her valuable edition services and feedback on the content of this article. 


\section{Additional files}

- File name: Additional file 1

- File format including the correct file extension for example .pdf, .xls, .txt, .pptx (including name and a URL of an appropriate viewer if format is unusual)

- Title of data

- Description of data

\section{References}

1. World Health Organization, UNFPA U and MS of PHealthAMD and D (AMDD). WHO | Monitoring emergency obstetric care. WHO. World Health Organization; 2013.

2. Sandall J, Tribe RM, Avery L, Mola G, Visser GH, Homer CS, et al. Short-term and long-term effects of caesarean section on the health of women and children. Vol. 392, The Lancet. Lancet Publishing Group; 2018. p. 1349-57.

3. Betran AP, Torloni MR, Zhang JJ, Gülmezoglu AM, WHO Working Group on Caesarean Section. WHO Statement on Caesarean Section Rates. BJOG Int J Obstet Gynaecol. 2016 Apr;123(5):667-70.

250 4. Betrán AP, Ye J, Moller A-B, Zhang J, Gülmezoglu AM, Torloni MR. The Increasing Trend in Caesarean Section Rates: Global, Regional and National Estimates: 19902014. Zeeb H, editor. PLOS ONE. 2016 Feb 5;11(2):e0148343.

5. Boerma T, Ronsmans C, Melesse DY, Barros AJD, Barros FC, Juan L, et al. Global epidemiology of use of and disparities in caesarean sections. Vol. 392, The Lancet. Lancet Publishing Group; 2018. p. 1341-8.

6. Ortiz-Prado E, Castillo TA, Olmedo-López M, Armijos L, Ramírez D, Iturralde AL. Cesarean section rates in Ecuador: A 13-year comparative analysis between public and private health systems. Rev Panam Salud PublicaPan Am J Public Health. 2017;41.

7. Faisal-Cury A, Menezes PR, Quayle J, Santiago K, Matijasevich A. The relationship 260 between indicators of socioeconomic status and cesarean section in public hospitals. Rev Saude Publica. 2017 Mar 23;51(0):14.

8. Barros FC, Matijasevich A, Maranhao AGK, Escalante JJ, Rabello Neto DL, Fernandes RM, et al. Cesarean sections in Brazil: will they ever stop increasing? Rev Panam SALUD PUBLICA-PAN Am J PUBLIC Health. 2015;38(3):217-25.

265 9. Mariana Duhau AB, Escobar LP, Fasola ML, Gomariz SraV. SIP-G Indicadores básicos-República Argentina, 2017-2-A., Dirección Maternidad, Infancia, y Adolescencia. Area de monitoreo y evaluación.

10. Souza J, Betran A, Dumont A, de Mucio B, Gibbs Pickens C, Deneux-Tharaux C, et al. A global reference for caesarean section rates (C-Model): a multicountry cross-sectional study. BJOG Int J Obstet Gynaecol. 2016 Feb;123(3):427-36. 
11. Mazzoni A, Althabe F, Gutierrez L, Gibbons L, Liu NH, Bonotti AM, et al. Women's preferences and mode of delivery in public and private hospitals: a prospective cohort study. BMC Pregnancy Childbirth. 2016;16(34).

12. Mazzoni A, Althabe F, Liu N, Bonotti A, Gibbons L, Sánchez A, et al. Women's preference for caesarean section: a systematic review and meta-analysis of observational studies. BJOG Int J Obstet Gynaecol. 2011 Mar;118(4):391-9.

13. Coates D, Thirukumar P, Spear V, Brown G, Henry A. What are women's mode of birth preferences and why? A systematic scoping review. Women Birth. 2020 Jul 1;33(4):323-33.

280 14. Ramos S, Romero M, Perrotta C, Sguassero Y, Straw C, Gialdini C, et al. Optimizing the use of cesarean section in Argentina: design and methodology of a formative research for the development of interventions. Reprod Health. 2021 Dec;18(1).

15. Adams WC. Conducting Semi-Structured Interviews. In: Handbook of Practical Program Evaluation. Hoboken, NJ, USA: John Wiley \& Sons, Inc.; 2015. p. 492-505.

16. Von Elm E, Altman DG, Egger M, Pocock SJ, Gøtzsche PC, Vandenbroucke JP. The Strengthening the Reporting of Observational Studies in Epidemiology (STROBE) statement: Guidelines for reporting observational studies. PLoS Med. 2007 Oct;4(10):1623-7.

17. Hosmer D; Lemeshow S. Aplied logistic Regression. Second Edi. John Wiley \& Sons, Ltd; 2000.

18. Bohren MA, Hofmeyr GJ, Sakala C, Fukuzawa RK, Cuthbert A. Continuous support for women during childbirth. Vol. 2017, Cochrane Database of Systematic Reviews. John Wiley and Sons Ltd; 2017.

19. Long Q, Kingdon C, Yang F, Renecle MD, Jahanfar S, Bohren MA, et al. Prevalence of and reasons for women's, family members', and health professionals' preferences for cesarean section in China: A mixed-methods systematic review. PLoS Med. 2018 Oct $1 ; 15(10)$.

20. Torloni MR, Betrán AP, Montilla P, Scolaro E, Seuc A, Mazzoni A, et al. Do Italian women prefer cesarean section? Results from a survey on mode of delivery preferences. BMC Pregnancy Childbirth. 2013 Mar 26;13(1):78.

21. Wang E. Requests for cesarean deliveries: The politics of labor pain and pain relief in Shanghai, China. Soc Sci Med. 2017 Jan 1;173:1-8.

22. Fioretti BTS, Reiter M, Betrán AP, Torloni MR. Googling caesarean section: A survey on the quality of the information available on the Internet. BJOG Int J Obstet Gynaecol. 2015 Apr 1;122(5):731-9.

23. Hodnett ED, Gates S, Hofmeyr GJ, Sakala C. Continuous support for women during childbirth. Cochrane Database Syst Rev. 2013 Jul 15;7:CD003766. 
24. Betrán AP, Temmerman M, Kingdon C, Mohiddin A, Opiyo N, Torloni MR, et al. Interventions to reduce unnecessary caesarean sections in healthy women and babies. Vol. 392, The Lancet. Lancet Publishing Group; 2018. p. 1358-68.

25. Torloni MR, Campos Mansilla B, Merialdi M, Betrán AP. What do popular Spanish women's magazines say about caesarean section? A 21-year survey. Vol. 121, BJOG: An International Journal of Obstetrics and Gynaecology. Blackwell Publishing Ltd; 2014. p. 548-55.

315 26. Torloni MR, Daher S, Betrán AP, Widmer M, Montilla P, Souza JP, et al. Portrayal of caesarean section in Brazilian women's magazines: 20 year review. BMJ. $2011 \mathrm{Feb}$ $5 ; 342(7792): 324$.

27. Nicholls J, David AL, Iskaros J, Lanceley A. Consent in pregnancy: A qualitative study of the views and experiences of women and their healthcare professionals. Eur J Obstet Gynecol Reprod Biol. 2019 Jul 1;238:132-7.

28. Schantz C, de Loenzien M, Goyet S, Ravit M, Dancoisne A, Dumont A. How is women's demand for caesarean section measured? A systematic literature review. Vol. 14, PLoS ONE. Public Library of Science; 2019.

29. Loke AY, Davies L, Mak YW. Is it the decision of women to choose a cesarean section as the mode of birth? A review of literature on the views of stakeholders. BMC Pregnancy Childbirth. 2019 Aug 9;19(1).

30. Kingdon C, Downe S, Betran AP. Non-clinical interventions to reduce unnecessary caesarean section targeted at organisations, facilities and systems: Systematic review of qualitative studies. 2018;

330 31. WHO Steering group. WHO recommendations non-clinical interventions to reduce unnecessary caesarean sections. 2018.

32. Chen I, Opiyo N, Tavender E, Mortazhejri S, Rader T, Petkovic J, et al. Non-clinical interventions for reducing unnecessary caesarean section. Vol. 2018, Cochrane Database of Systematic Reviews. John Wiley and Sons Ltd; 2018. p. CD005528. 


\section{Supplementary Files}

This is a list of supplementary files associated with this preprint. Click to download.

- Womenssurvey.pdf 